\title{
Assessment of neonatal sepsis and associated factors among neonates admitted neonatal intensive care unit in selected public hospitals in Somali region, Ethiopia
}

\author{
Abdikani Nur®, Mohamed Osman® \\ Department of Public Health, College of Medicine and Health Science, Jigjiga University, Jigjiga, Ethiopia
}

\section{ABSTRACT}

Objectives: To assess neonatal sepsis and associated factors among neonates admitted neonatal intensive care unit in selected public hospitals in Somali region, Ethiopia.

Methods: Institution based cross sectional study design was conducted in selected public hospitals. Data was collected using structured questionnaire adopted from other literature, entered into Epi-data version 3.1 and then was exported to SPSS version 23 for analysis. Frequency was used for descriptive analysis. Bivariate analysis was used to determine the association between different risk factors and the outcome variable. Those variables which have significant association at 5\% significance level and fulfilling the minimum requirement of 0.2 level of significance with neonatal sepsis was entered for further analysis to multivariate analysis, significance was taken at $\alpha=<0.05$.

Results: The overall prevalence of this study was $42.9 \% \mathrm{CI}=(38.4-47.8)$ and associated factors was age of the neonate $\mathrm{AOR}=0.085(\mathrm{CI}=0.01,0.73)$, Residence shown $\mathrm{AOR}=2.567(\mathrm{CI}=1.01,6.5)$ Gestational age $\mathrm{AOR}=1.869(\mathrm{CI}=1.05,3.31)$, Meconium stained Amniotic fluid AOR = $2.718(\mathrm{CI}=1.89,6.74)$, Antenatal care $\mathrm{AOR}=8.933(\mathrm{CI}=4.9,15.9)$, and Mechanical ventilation after birth $\mathrm{OR}=3.376(\mathrm{CI}=1.65,6.88)$.

Conclusions: The present study found that the overall prevalence of neonatal sepsis in selected hospitals was 42.9\%. The study identified, Age of the neonate, Residence, Gestational age, Meconium stained amniotic fluid. Antenatal care, Mechanical ventilation after birth. The findings underscore the importance of routine assessment and close monitoring of neonates. It is therefore recommended to have more skilled health personnel and advanced equipment while providing maternal and new-born health care services.

Keywords: Neonatal sepsis, associated factors, neonates admitted neonatal intensive care unit, selected public hospitals, Somali region, Ethiopia 2017/2018.

Cepsis is defined as a clinical syndrome describe by a set of hemodynamic, respiratory and metabolic shifts secondary to an infectious process that can prompt an unusual systemic inflammatory response syndrome of the organism (SIRS) [1].

Neonatal sepsis is a defined as a clinical syndrome characterized by signs and symptoms of infection in an infant 28 days of life or younger. And it is a major cause of morbidity and mortality in newborns [2]. Early onset of neonatal sepsis defined as occurring in the first 3 days of life and is caused by bacterial pathogens transmitted vertically from mother to infant before or during delivery while late-onset sepsis (LOS) is sepsis occurring after $72 \mathrm{~h}$ in NICU infants 
and 7 days of life in term infants, has been variably defined as occurring up to the age of 90 or 120 days, and may be caused by vertically or horizontally acquired pathogens [3]. According to WHO the epidemiology of sepsis is better known in adults than in children, yet neonatal and child death due to sepsis is a major problem. There are an estimated 2.9 million deaths worldwide from sepsis every year $(44 \%$ of them in children under 5 years of age) and one quarter of these is due to neonatal sepsis [4]. In 2012, an estimated 6.9 million (uncertainty range $5.5-8.3$ million) possible severe bacterial infections occurred in neonates in Latin America, South Asia, and sub-Saharan Africa [5]. Neonatal sepsis is the third most common cause of death in this age group with an estimated 0.401 millions of deaths (uncertainty range [0.2800.522 ], $6.8 \%$ [4.7-8.6]) in 2015, the vast majority of which are in developing countries [6].

Another report showed Globally the leading causes of death among children under age 5 included preterm birth complications (18\%), pneumonia (16\%), and intrapartum related events (12\%), congenital anomalies $(9 \%)$, diarrhea (8\%), neonatal sepsis $(7 \%)$ and malaria (5\%) [7].

Based on the 2014 WHO/CHERG estimates for Ethiopia the major causes of children less than 5 years mortality, were acute respiratory infection (ARI) $(18 \%)$, diarrhea $(9 \%)$, prematurity $(11 \%)$, sepsis $(9 \%)$, birth asphyxia (14\%), injuries (6\%), and measles $(2 \%)$ and others (21\%) [8].

As it shows the 2016 Ethiopia Demographic and Health Surveys (EDHS), neonatal mortality declined from 49 deaths per 1,000 live births in 2000 to 29 deaths per 1,000 births in 2016, a reduction of $41 \%$ over the past 16 years and in Somali region is 41 deaths per 1000 live births [9].

Numerous factors associated with the high mortality due to infections were due to delays in the early identification and treatment of newborns with infection, particularly; under-recognition of illness, delay in care seeking at the household level, delay in initiation of treatment, and lack of access to both appropriately trained health workers and to high quality services to manage sepsis. It is particularly affecting that many neonatal deaths occur in the community, without the newborn ever having contact with the appropriate health care services $[10,11]$.

The third Sustainable Development Goal for child health (United Nations 2015), which aims to end preventable deaths of neonates and children under five years of age by 2030, may not be met without substantial reduction of neonatal sepsis-specific mortality in the developing countries [12].

In the world and especially sub-Saharan African countries Newborn survival is a problem of great concern, although Ethiopia made big efforts on maternal and child health programs and advancing healthcare system, most of the neonatal admission to the NICU with sepsis, has been increased. Many studies have been done in Ethiopia but there were limited studies tried to substantiate the risk factors of neonatal sepsis in the study areas (pastoral areas) of the country as a whole. This study was therefore, carried out to find out neonatal sepsis and factors contributing among neonates in three public hospitals of Somali region, Ethiopia.

\section{METHODS}

\section{Study Area}

This, study was conducted in Jigjiga, Godey, Kabri-dahar hospitals of Somali Region, Eastern Ethiopia from December-May2017/2018. Jigjiga town is the capital city of Somali regional state located 626 km east from Addis Ababa, capital city of Ethiopia \& $101 \mathrm{~km}$ east from Harar town. As of 2009 EFY Jigjiga city has total population of 199,431 of which 45,570 are in reproductive age group (15-49 years). Current it has 30 Kebles of which 20 are urban $\& 10$ are rural. Majority of people are Somali ethnic (97\%) \& Muslim in religion (98\%). People of Jigjiga city are mostly agro-pastoral, their main source of income depends on farming and livestock, other source of income like small business, government employees etc. Jigjiga city has one Referral hospital, one Zonal hospital, two health centers \& ten health posts, Two public hospitals and two health center are providing delivery service [13].

Godey Council is located in the Shebelle Zone of the Somali Region it is located $600 \mathrm{~km}$ away from Regional capital, Jigjiga (capital town of Ethiopian Somali region). It is Semi-arid weather condition and low altitude with flat land surfaces [14]. Administratively, it consists 10 Kebeles. Total population of the council is estimated to be 75,000 in 2016 (33,000 male and 
42,000 females). In terms of health delivery system,
the council has one Hospital, 1 NGO clinics and 4 Health Posts [15].

Based on figures from the Central Statistical Agency in 2005, Kabri-dahar has an estimated total population of 100,191 of whom 51,327 are men and 48,864 are women. The two largest ethnic groups reported in this town were the Somali $(89.02 \%)$, and the Amhara (2.58\%); all other ethnic groups made up $8.4 \%$ of the population. City has one zonal hospital and two health centers 2 heath posts [14].

\section{Study Design}

An institution based cross-sectional study design was employed.

\section{Source Population}

All neonates who were admitted to NICU of hospitals during the study period in Somali region were the study population for this study.

\section{Study Population}

All new-born $\leq 28$ days of life and who were admitted in neonatal ward randomly selected to involve in the study.

Inclusion Criteria: All neonates who were admitted to intensive care unit were included in this study.

Exclusion Criteria: Neonates who were early discharged before data collection was completed but only card was available, incomplete patient chart information, and died on arrival (neonates expired without taking any investigation and treatment on arrival) were excluded from this study.

\section{Sampling Procedure and sampling technique}

There are nine regional hospitals in Somali region and three of them were selected by using lottery method (Fig. 1). The number of study subjects for each hospital was allocated proportionally after identifying the number of admissions in each hospital for the specified period (last three months). The number of admission in karamara was 5210; Gode hospital was 3460 and 1571 was Kabri-dahar hospital.

Proportionally allocated sample size of 203, 135 and 61 for karamara, Gode and Kabri-daharHospitals respectively. Participants' was selected consecutively

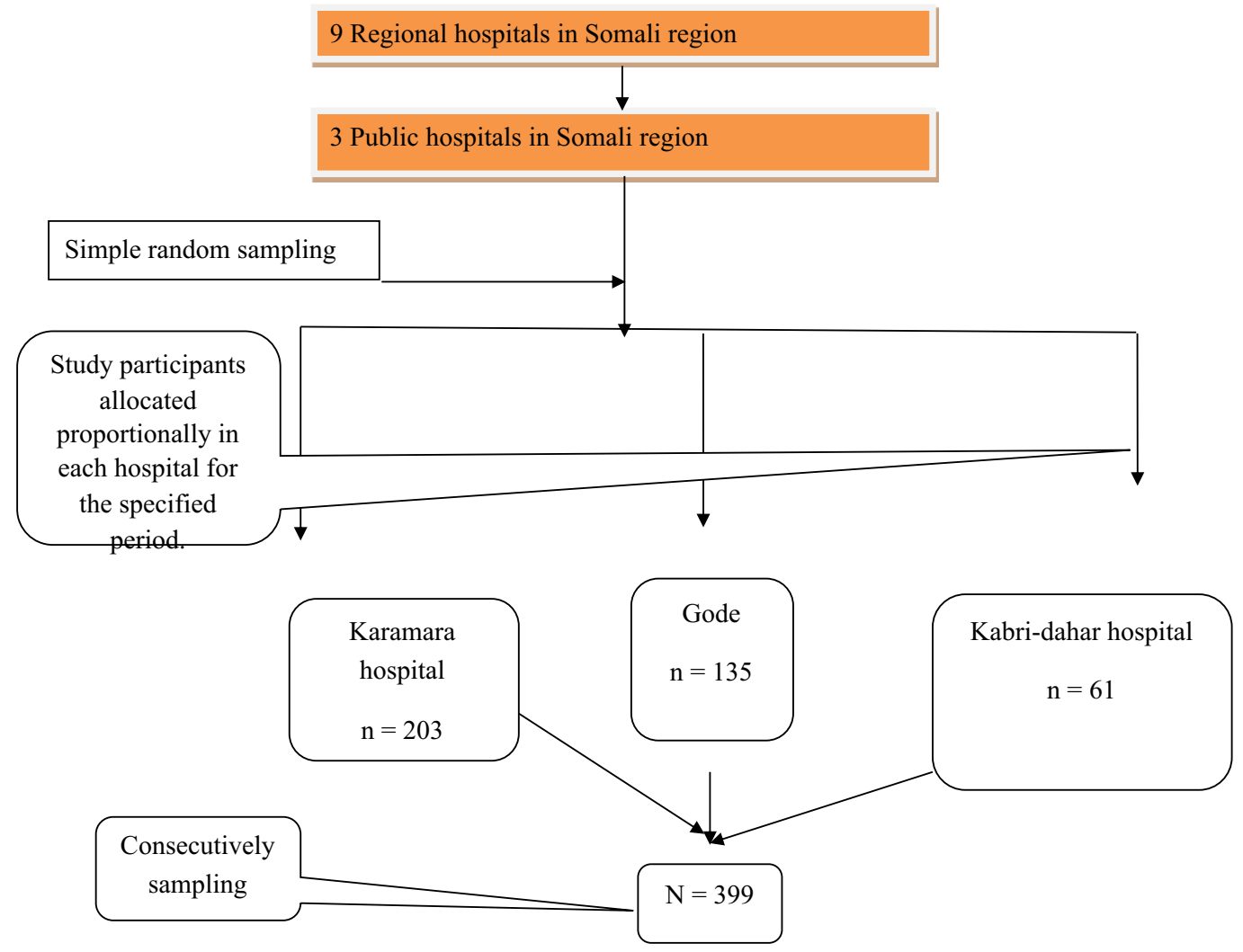

Fig. 1. Sampling Procedure and sampling technique 
recruitment and was continued until the sample size allocated fulfilled/met.

\section{Data Collection Technique and Tools}

A pre-tested interviewer-administered questionnaire and check lists were used to collect the data. The tools were developed by reviewing different literatures. The information was collected during the admission of neonate to NICU and by reviewing the registration book records in labor ward, NICU, and gynecologic ward in each hospital.

\section{Sample Size Determination}

The sample size was determined by using single population proportion formula and the proportion was taken from the previous literature in Ethiopia. According to study conducted at Black Lion specialized hospital, the prevalence of neonatal sepsis was $44.7 \%$ and by considering $95 \%$ confidence interval $(\mathrm{CI})$ and $5 \%$ marginal error the, sample size was calculated as follows:

$$
\text { Where } n=\left(Z_{\partial / 2}\right)^{2} \frac{P(1-p)}{d^{2}}
$$

$\mathrm{n}=$ required sample size

$\mathrm{Z}=$ the standard normal deviation at $95 \%$ confidence interval; $=1.96$

$\mathrm{P}=$ prevalence of neonatal sepsis among neonates admitted in NICU with prevalence of $44.7 \%$ (16).

$\mathrm{d}=$ margin of error that can be tolerated, $5 \%(0.05)$

$1-p=$ proportion of population that do not possess the character of interest.

Therefore,

$$
\mathrm{n}=(\mathrm{Z} \partial / 2) 2 \mathrm{p}(1-\mathrm{p}) / \mathrm{d} 2=(1.96) 2(0.447)(0.553) /
$$
$(0.05) 2=380$

By adding non response rate 5\%, our total sample size was 399 neonates.

\section{Study Variables}

\section{Dependent Variable: Neonatal sepsis}

Independent Variable: Socio-demographic characteristics of mothers, socio-demographic characteristics of neonates, and obstetric characteristics of mothers were independent variables for this study.

\section{Data Quality Control}

Three training was given for two data collectors in each hospital with an academic background of diploma/degree in nursing/midwifery working outside the study hospitals The training was focused on introducing the data collection tools, the initial and end of the data collection period, how they are collected the data, using the time wisely, data handling, and submit the collected data. Pretest was done 5\% to pave the way any solution/modification in appropriate time. Data completeness was checked, cleaned and compiled by the investigator on daily basis.

\section{Operational Definition}

Neonatal Sepsis: neonate with sepsis within 0-28 days of life

Early Onset Neonatal Sepsis: neonate with sepsis within $0-7$ days

Late Onset Neonatal Sepsis: neonate with sepsis within 8-28 days

Low Birth Weight: weight of the child

\section{Ethical Consideration}

Ethical clearance letter was acquired from ethical Review Board of Jigjiga University, and after explaining about the purpose and the possible benefit of the study permission to gather datawas secured from regional health bureau and delivered to public hospital administrators. Confidentiality was maintained at all levels of the study.

\section{Statistical Analysis}

The data was cleaned for inconsistencies and missing values and modification was considered as necessitate, coded and entered into Epi-data version 4.1 and then was exported to SPSS (Statistical Package for Social science) version 20 for analysis. Frequency was used for the descriptive, after assessing the normality of distribution of the data; Bivariate and multivariate analyses were used to assess the association between each independent variable and the outcome variable by using binary logistic regression. All variables with $\mathrm{P}<0.25$ in the Bivariate analysis were included in the final model of multivariate analysis in order to control all possible confounders. The degree of association between dependent and independent variables was examined using odds ratio with $95 \% \mathrm{CI}$. $\mathrm{P}$-value less than 0.05 was considered as significance level for associations between dependent and independent variables. Confidence interval of $95 \%$ was 
used to be examined the precision of the study and the level of significance was taken at $\alpha=<0.05$. Finally, result was presented in Texts, and Tables.

\section{RESULTS}

\section{Socio-demographic Characteristics}

A total of 380 neonates were involved in the study, with 95\% response rate from December 2017 to May 2018 in three selected public hospitals (Karamara, Gode, Kabridahar). Regarding residence 340 (89.5\%) resided urban, and 193 (50.8) of those were male and $61(37.4 \%)$ developed neonatal sepsis. Concerning age of the neonates $365(96.1 \%)$ aged between 0-7 days among these 149 (91.4\%) developed neonatal sepsis, regarding maternal age $160(42.1 \%)$ and 85 (52.1\%) their neonates developed neonatal sepsis, Maternal education $274(72.1 \%)$ of the mothers had never go to school, 114 (69.9\%) of then had NS (Table 1).

\section{Prevalence of Neonatal Sepsis}

This study, the prevalence and associated risk factors of neonatal sepsis of neonates admitted in the three selected hospitals with in the December-May $2017 / 2018$. The total prevalence of this study was $42.9 \%$, with CI $=(37-46)$ (Table 2$)$.

\section{Neonatal Characteristics}

In terms of birth weight of the neonates, 286 $(75.3 \%)$ of them had normal birth weight $(<2.5 \mathrm{~kg})$ and of these $139(85.3 \%)$ had EONS. Regarding gestational age $210(55.3 \%)$ were term deliveries 102 (62.6\%) had neonatal sepsis. About the Apgar score $323(85 \%)$ had $>7$ said to have Apgar score less than 7. About $225(67.1 \%)$ of neonates who were reported as to have birth asphyxia, $102(62.6 \%)$ of them developed neonatal sepsis (Table 3 ).

\section{Maternal Characteristics}

Among 206 (54.2\%) neonates who had history of maternal UTI and developed NS were 77 (47.2\%) during delivery and $151(39.7 \%)$ had maternal history of ANC follow up, among these 113 (69.3) had neonatal sepsis, about $49(12.9 \%)$ of the mothers of the neonates had premature rupture of membrane and 24 (14.7\%) developed neonatal sepsis, 26 (81.3\%) duration $<18$ hours. Regarding meconium stained amni-

\section{Table 1. Socio-demographic Characteristics}

\begin{tabular}{|c|c|c|c|c|}
\hline \multirow[t]{3}{*}{$\mathbf{S} / \mathbf{N}$} & \multirow[t]{3}{*}{ Variables } & \multirow[t]{3}{*}{ Category } & \multicolumn{2}{|c|}{ Neonatal sepsis } \\
\hline & & & Yes & No \\
\hline & & & Number (\%) & Number $(\%)$ \\
\hline \multirow[t]{2}{*}{1} & Residence & Urban & $138(84.7)$ & $202(93.1)$ \\
\hline & & Rural & $25(15.3)$ & $15(6.9)$ \\
\hline \multirow[t]{2}{*}{2} & Sex of the neonate & Male & $61(37.4)$ & $132(60.8)$ \\
\hline & & Female & $102(62.6)$ & $85(39.2)$ \\
\hline \multirow[t]{2}{*}{3} & age of the neonate & $0-7$ days & $149(91.4)$ & $216(99.5)$ \\
\hline & & $8-28$ days & $14(8.6)$ & $1(0.5)$ \\
\hline \multirow[t]{4}{*}{4} & Maternal age & $<19$ years & $16(9.8)$ & $75(34.6)$ \\
\hline & & 20-30years & $85(52.1)$ & $75(34.6)$ \\
\hline & & 30-40years & $52(31.9)$ & $57(26.3)$ \\
\hline & & $>41$ years & $10(6.1)$ & $10(4.6)$ \\
\hline \multirow[t]{3}{*}{5} & Maternal education & Never go to school & $114(69.9)$ & $160(73.7)$ \\
\hline & & Primary & $45(27.6)$ & $48(22.1)$ \\
\hline & & High school and above & $4(2.5)$ & $9(4.1)$ \\
\hline \multirow[t]{2}{*}{6} & Parity & Nulliparous & $36(22.1)$ & $112(51.6)$ \\
\hline & & Multiparious & $127(77.9)$ & $105(48.4)$ \\
\hline
\end{tabular}


Table 2. Prevalence of neonatal sepsis

\begin{tabular}{lccc}
\hline Variable & Category & Frequency & Percent \\
\hline $\begin{array}{l}\text { 7. Neonatal } \\
\text { sepsis }\end{array}$ & Yes & 163 & 42.9 \\
& No & 217 & 57.1 \\
\hline
\end{tabular}

otic fluid $60(15.8 \%)$ of the mothers had MSAF and $14(8.6 \%)$ during delivery and 14 (8.6\%) developed neonatal sepsis. Regarding duration of labor 255 (67.1\%) labored between 6-12 hours of these 103 $(63.2 \%)$ had NS (Table 4).

\section{Medical Related Factors}

Regarding mode of delivery about 275 (72.4\%) delivered spontaneously and $117(71.8 \%)$ had neonatal sepsis and also 305 (80.3\%). About 154 (40.5\%) were resuscitated by mechanical ventilation, $106(65 \%)$ developed neonatal sepsis (Table 5).

Multivariate Analysis of the Association between Neonatal Sepsis and Other Neonatal Variables In this study both Bivariate and multivariate level of analysis was investigated to determine the association between late onset neonatal sepsis and other different

Table 3. Neonatal characteristics

\begin{tabular}{llccc}
\hline S/N & Variables & Category & \multicolumn{2}{c}{ Neonatal sepsis } \\
& & Yes & No \\
& & Number (\%) & Number (\%) \\
\hline 8 & Birth weight & $<2.5 \mathrm{~kg}$ & $24(14.7)$ & $23(10.6)$ \\
& & $2.5-4 \mathrm{~kg}$ & $139(85.3)$ & $194(89.4)$ \\
9 & Gestational age & $<37$ weeks & $61(37.1)$ & $109(50.2)$ \\
& & $>37$ weeks & $102(62.6)$ & $108(49.8)$ \\
10 & Apgarscore $<7$ & $<7$ & $22(13.5)$ & $35(16.1)$ \\
& & $>7$ & $141(86.5)$ & $182(83.9)$ \\
11 & Birth asphyxia & Yes & $102(62.6)$ & $153(70.5)$ \\
12 & & No & $61(37.4)$ & $64(29.5)$ \\
& Not breast feeding & Yes & $98(60.1 \%)$ & $138(63.6 \%)$ \\
13 & & No & $65(39.9 \%)$ & $79(36.4 \%)$ \\
& Neonatal fever & Yes & $78(47.9 \%)$ & $99(45.6 \%)$ \\
\hline
\end{tabular}

Table 4. Maternal characteristics

\begin{tabular}{llccc}
\hline S/N & Variables & Category & \multicolumn{2}{c}{ Neonatal sepsis } \\
& & & Yes & No \\
\hline 14 & Maternal UTI & Yes & $77(47.2)$ & $129(59.4)$ \\
& & No & $86(52.8)$ & $88(40.6)$ \\
15 & ANC & Yes & $113(69.3)$ & $38(17.5)$ \\
& & No & $50(30.7)$ & $179(82.5)$ \\
16 & History of chorioamnionitis & Yes & $9(37.5)$ & $154(43.3)$ \\
& & No & $15(62.5)$ & $202(56.7)$ \\
17 & PROM & Yes & $24(14.7)$ & $25(11.5)$ \\
18 & If yes duration & No & $139(85.3)$ & $192(88.5)$ \\
& & $<18 \mathrm{hrs}$ & $13(76.5)$ & $13(86.7)$ \\
19 & MSAF & $>18 \mathrm{hrs}$ & $4(23.5)$ & $2(13.3)$ \\
& & Yes & $14(8.6)$ & $46(21.2)$ \\
20 & Duration of labour & No & $149(91.4)$ & $171(78.8)$ \\
& & $<6$ hours & $59(36.2)$ & $63(29)$ \\
& & $6-12 \mathrm{hrs}$ & $103(63.2)$ & $152(70)$ \\
\hline
\end{tabular}


risk factors. Variables those have significant association on Bivariate analysis was taken to multivariate analysis to control the confounders. The current study found that age of the neonate found to be significantly associated with neonatal sepsis, neonates aged 8-28 days were protective by $91 \%$ compared to neonates aged 0-7 days. $\mathrm{AOR}=0.085(\mathrm{CI}=0.01,0.73)($ Table $6)$. Regarding the residence, neonates who were from urban residence were 2.5 times more likely to develop neonatal sepsis compared to neonates from rural residence. $\mathrm{AOR}=2.567$ ( $\mathrm{CI}=1.01,6.5)$. Gestational age, neonates who gestational age were $<37$ weeks of gestation were 1.8 times more likely to develop neonatal sepsis compared to neonates who gestational age were 37-42 weeks AOR=1.869 (CI=1.05, 3.31). Concerning antenatal care, neonates who's their mother had not history of ANC were 8.9 times more likely to develop neonatal sepsis compared to neonates who's their mother had history of ANC flow up AOR= 8.933 $(\mathrm{CI}=4.9,15.9)$. Neonates who's their mother had meconium stained amniotic fluid were 2.7 times more likely to develop neonatal sepsis compared to neonates who's their mother had not meconium stained amniotic fluid $\mathrm{AOR}=2.718(\mathrm{CI}=1.89,6.74)$. About ventilation, neonates who had mechanical ventilation were 3.3 times more likely to develop neonatal sepsis compared to neonates who had not mechanical ventilation after birth $\mathrm{AOR}=3.376(\mathrm{CI}=1.65,6.88)$ (see Table 6$)$.

\section{DISCUSSION}

This study, the prevalence and associated risk factors of neonatal sepsis of neonates admitted in the three selected hospitals with in the December-May $2017 / 2018$. The total prevalence of this study was $42.9 \%$, with CI $=(38.4-47.8)$ this was near to compared to study conducted in Black lion specialized hospital in 2010 which was $44.7 \%$ [16]. And also to different studies in different countries showed very close figures India 35.1\% Saudi Arabia (37\%), Nigeria 33.1\% Tanzania (31.4\%) [17-20]. But its large different study finding in Mexico this could be due to the difference in study design, and the sample size which shown 4.3 $\%$ considerable low when compared other studies. This difference may have been contributed by the presence of more skilled personnel in Mexico and advanced or modernized equipment compared to other studies [21].

The current study found that age of the neonate found to be significantly associated with neonatal sepsis, neonates aged 8-28 days were protective by $91 . \%$ compared to neonates aged 0-7 days. $\mathrm{AOR}=0.085$ $(\mathrm{CI}=0.01,0.73)$ compared to Study conducted in Nigeria showed almost similar significance $<3$ days compared to above these days above. the possible explanation of the difference can be the sample included who were age of less than three days [22]. This could

\section{Tablo 5. Medical related factors}

\begin{tabular}{llccc}
\hline S/N & Variables & Category & \multicolumn{2}{c}{ Neonatal sepsis } \\
& & Yes & No \\
& & Number (\%) & Number (\%) \\
\hline 21 & Mode of delivery & Spontaneous & $117(71.8)$ & $158(72.8)$ \\
& & C/S & $15(9.2)$ & $25(11.5)$ \\
& & Instrumental & $31(19)$ & $34(15.7)$ \\
22 & Place of delivery & Hospital & $124(76)$. & $181(83.4)$ \\
& & Health center & $30(18.4)$ & $30(13.8)$ \\
& & Clinics & $2(1.2)$ & $1(0.5)$ \\
& & Health center & $7(4.3)$ & $5(2.3)$ \\
& Mechanical ventilation & Yes & $23(20.5)$ & $140(52.2)$ \\
& & No & $89(79.5)$ & $128(47.8)$ \\
\hline
\end{tabular}


Table 6. Multivariate analysis of the association between NS and other neonatal variables

\begin{tabular}{|c|c|c|c|c|c|c|}
\hline \multirow[t]{3}{*}{ Variables } & \multirow[t]{3}{*}{ Category } & \multicolumn{5}{|c|}{ Neonatal sepsis } \\
\hline & & \multicolumn{2}{|c|}{$\begin{array}{l}\text { Neonatal } \\
\text { sepsis }\end{array}$} & \multirow[t]{2}{*}{ COR (CI: 95\%) } & \multirow[t]{2}{*}{ AOR $[95 \% C I]$} & \multirow[t]{2}{*}{$p$ value } \\
\hline & & Yes & No & & & \\
\hline \multirow[t]{2}{*}{ Sex of the neonate } & Male & 61 & 132 & $2.5(1.70,3.94)$ & $1.519(0.87,2.63)$ & 0.127 \\
\hline & Female & 102 & 85 & 1 & 1 & \\
\hline \multirow[t]{2}{*}{ Age of the neonate } & 0-7days & 63 & 173 & 1 & 1 & \\
\hline & 8-28 days & 100 & 44 & $0.16(0.10,0.25)$ & $0.085(0.01,0.73)$ & 0.025 \\
\hline \multirow[t]{4}{*}{ Maternal age } & $<19$ years & 16 & 75 & $4.68(1.67,13.1)$ & $2.504(0.64,9.7)$ & 0.186 \\
\hline & 20-30 years & 85 & 75 & $0.88(0.34,2.23)$ & $0.930(0.30,2.80)$ & 0.897 \\
\hline & $30-40$ years & 52 & 57 & $1.09(0.42,2.84)$ & $1.06(0.34,3.24)$ & 0.919 \\
\hline & $>41$ years & 10 & 10 & 1 & 1 & \\
\hline \multirow[t]{2}{*}{ Parity } & Nulliparous & 36 & 112 & $3.7(2.38,5.93)$ & $1.79(0.85,3.76)$ & 0.123 \\
\hline & Multiparious & 127 & 105 & 1 & 1 & \\
\hline \multirow[t]{2}{*}{ Residence } & Urban & 138 & 202 & $2.44(1.24,4.8)$ & $2.567(1.01,6.5)$ & 0.047 \\
\hline & Rural & 25 & 15 & 1 & 1 & \\
\hline \multirow[t]{2}{*}{ Gestational age } & $<37$ weeks & 61 & 109 & $(1.15,2.55)$ & $1.869(1.05,3.31)^{*}$ & 0.032 \\
\hline & 37-42 weeks & 102 & 108 & 1 & 1 & \\
\hline \multirow[t]{2}{*}{ Birth asphyxia } & Yes & 102 & 153 & $1.43(0.92,2.20)$ & $0.943(0.53,1.66)$ & 0.840 \\
\hline & No & 61 & 64 & 1 & 1 & \\
\hline \multirow[t]{2}{*}{ Maternal UTI } & Yes & 77 & 129 & $1.63(1.08,2.4)$ & $1.287(0.73,2.25)$ & 0.376 \\
\hline & No & 86 & 88 & 1 & 1 & \\
\hline \multirow[t]{2}{*}{ ANC } & Yes & 113 & 38 & 1 & 1 & \\
\hline & No & 50 & 179 & $10.6(6.56,172)$ & $8.933(4.9,15.9)$ & $<0.001$ \\
\hline \multirow[t]{2}{*}{ MSAF } & Yes & 14 & 46 & $2.86(1.5,5.4)$ & $2.718(1.89,6.74)$ & 0.031 \\
\hline & No & 149 & 171 & 1 & 1 & \\
\hline \multirow{2}{*}{$\begin{array}{l}\text { Mechanical } \\
\text { ventilation }\end{array}$} & Yes & 23 & 140 & $4.23(2.52,71)$ & $3.376(1.65,6.88)$ & 0.001 \\
\hline & No & 89 & 128 & 1 & 1 & \\
\hline
\end{tabular}

be due neonates with smaller ages had low immunity compared to those aged greater than first week of life. This difference might be due to the nature of age transfer as the physiologic events and changes associated with it.

Regarding the residence, neonates who were from urban residence were 2.5 times more likely to develop neonatal sepsis compared to neonates from rural residence. $\mathrm{AOR}=2.567(\mathrm{CI}=1.01,6.5)$ this may be most of the neonates from urban residence were born health facility and they might acquire the nosocomial infection. Other thing is that some of the neonates were living urban slum areas where hygiene and sanitation, maternal and child health services are most commonly low.

Gestational age, neonates who gestational age were $<37$ weeks of gestation were 1.8 times more likely to develop neonatal sepsis compared to neonates 
who gestational age were $37-42$ weeks $\mathrm{AOR}=1.869$ $(\mathrm{CI}=1.05,3.31)$.Compared to other studies also revealed Preterm delivery as significant risk factors for neonatal sepsis and in fact this factors has been well documented in previous studies [16, 23], In similar study conducted in Bishoftu city indicated that, preterm neonates did not showed significant association with the occurrence of neonatal sepsis [24] this may be due to health care service available or similarity of the design of the study used.

Concerning antenatal care, neonates who's their mother had not history of ANC were 8.9 times more likely to develop neonatal sepsis compared to neonates who's their mother had history of ANC flow up $\mathrm{AOR}=8.933(\mathrm{CI}=4.9,15.9)$. This was consistent with study done in Uganda which showed that lack of ANC was significantly associated with neonatal sepsis. Thus Antenatal care is predictor to neonatal sepsis and it suggests to increase the awareness and strength maternal reproductive health utilization including this very important care during pregnancy [25].

The presence of meconium stained amniotic fluid is a significant predictor of neonatal infection to this study, Neonates whose their mother had meconium stained amniotic fluid were 2.7 times more likely to develop neonatal sepsis compared to neonates who's their mother had not meconium stained amniotic fluid $\mathrm{AOR}=2.718(\mathrm{CI}=1.89,6.74)$.

Slightly more than this, studies conducted in Ghana displayed neonates who's their mother had meconium stained amniotic fluid were 3.6 times more likely to develop neonatal sepsis $\mathrm{AOR}=3.60(\mathrm{CI}=1.73$, 8.1) [26]. Other studies done in Ethiopia and Mexico agreed that specifically women who had meconium stained amniotic fluid were more likely to give birth to infants who suffered from neonatal sepsis compared to those without meconium stained amniotic fluid [23, 27]. There is also evidence supporting that when there ismeconium in amniotic fluid there is a greaterchance of the fetus being born with low Apgarscore, which unfortunately has earlier beenassociated with neonatal sepsis [16]. Normally it isexpected that the amniotic fluid should remain clear, however, in times of fetal hypoxia, it could be stained with meconium.

About ventilation, neonates who had mechanical ventilation were 3.3 times more likely to develop neonatal sepsis compared to neonates who had not mechanical ventilation after birth $\mathrm{AOR}=3.376$ (CI
$=1.65,6.88)$ Similar result of study conducted in Mexico revealed that mechanical ventilation was predictor to neonatal sepsis [23]. These similarities may be due deficiency of knowledge among some of the health care providers on aseptic precautions while resuscitating neonates in all settings.

\section{CONCLUSION}

The prevalence of neonatal sepsis in this study at selected public hospitals in Somali region is high. Study found that, the total prevalence of neonatal sepsis in selected hospitals was $42.9 \%$, with $\mathrm{CI}=(38.4-$ 47.8). The study identified Age of the neonate, Gestational age, Meconium stained amniotic fluid, antenatal care, Mechanical ventilation after birth as significant factors associated with neonatal sepsis. These findings suggest a possibility for routine assessment of neonates in order to identify risk factors for neonatal sepsis.

\section{RECOMMENDATIONS}

\section{Policy Makers General}

Based on the result the policy makers must It is therefore recommended to have more skilled health personnel and advanced equipment while providing maternal and neonatal health care services and the overall public health services more significantly health promotion and making available each laboratory equipment necessary.

\section{For Regional Health Bureau}

It must be focus on the prevention of risk factors rather than treating the disease after it occurs by planning necessary training program for health professionals who works in pediatrics and neonatal ward in these hospitals that helps them to improve their knowledge regarding the problem and strength maternal and child health services and making accessible each laboratory equipment necessary.

\section{For Health Professionals}

Based on the study finding, create awareness to the community by giving health education to mothers about different risk factors of sepsis during of ANC 
follow up which help them to screened and treated early. And when using treatment for neonatal sepsis they must consider the risk of misdiagnosis and mismanagement.

\section{Authors' Contribution}

Study Conception: AN; Study Design: MO; Supervision: MO; Funding: AN; Materials: AN; Data Collection and/or Processing: AN; Statistical Analysis and/or Data Interpretation: AN; Literature Review: MO; Manuscript Preparation: AN and Critical Review: MO.

\section{Conflict of interest}

The authors disclosed no conflict of interest during the preparation or publication of this manuscript.

\section{Financing}

The authors disclosed that they did not receive any grant during the conduction or writing of this study.

\section{Acknowledgement}

All praise is for Allah who enabled us to develop this research successfully. We would like to convey our heart full gratitude to my advisors Dr. Abdiwahab Hashi $(\mathrm{PhD})$ whom his valuable comments and advice and directions wouldn't be possible to execute this research. Our appreciation goes to Jigjiga University which gave us an opportunity to develop a research. Finally, we would like to appreciate people who had some involvement for the development and completion of this research.

\section{REFERENCES}

1. Dessì A, Pravettoni C, Ottonello G, Birocchi F, Cioglia F, Fanos V. Neonatal sepsis. Journal of Pediatric and Neonatal Individualized Medicine (JPNIM) 2014;3:e030273.

2. Edwards MS, Baker CJ. Sepsis in the newborn. In: Gershon A, Hotez P, Katz S, eds. Krugman's infectious diseases of children. 11th ed., Mosby, 2004: pp. 545-61.

3. Simonsen KA, Anderson-Berry AL, Delair SF, Davies HD. Early-onset neonatal sepsis. Clin Microbiol Rev 2014;27:21-47. 4. WHO, editor WHO Sepsis Technical Expert Meeting. Sepsis Technical Expert Meeting; 2018; Switzerland.

5. Seale AC, Blencowe H, Manu AA, Nair H, Bahl R, Qazi SA, et al. Estimates of possible severe bacterial infection in neonates in sub-Saharan Africa, south Asia, and Latin America for 2012: a systematic review and meta-analysis. Lancet Infect Dis
2014;14:731-41.

6. Liu L, Oza S, Hogan D, Chu Y, Perin J, Zhu J, et al. Global, regional, and national causes of under-5 mortality in 2000-15: an updated systematic analysis with implications for the Sustainable Development Goals. Lancet 2016;388:3027-35.

7. Lucia Hug DS, Kai Zhong and Danzhen You. Levels \& Trends in Child Mortality. New York: UN Inter-agency Group for Child Mortality Estimation, 2018.

8. Health TFDRoEMo. National Strategy for Newborn and Child Survival in Ethiopia. Addis Ababa, Ethiopia: Health MaCHDMo; 2015.

9. (Ethiopia) CSAC. Ethiopia Demographic and Health Survey 2016. Addis Ababa, Ethiopia: The DHS Program, ICF, Rockville, Maryland, USA; 2016.

10. Edmond K, Zaidi A. New approaches to preventing, diagnosing, and treating neonatal sepsis. PLoS Med 2010;7:e1000213. 11. Qazi SA, Stoll BJ. Neonatal sepsis: a major global public health challenge. Pediatr Infect Dis J 2009;28(1 Suppl):S1-2.

12. Ranjeva SL, Warf BC, Schiff SJ. Economic burden of neonatal sepsis in sub-Saharan Africa. BMJ Glob Health 2018;3:e000347.

13. FDRE. Population and Housing Census CSA; 2007.

14. CSA CSA. GODE. 2010.

15. Godey report. City council Health Office, 2016.

16. Shitaye D Asrat D, Woldeamanuel Y, Worku B. Risk factors and etiology of neonatal sepsis in Tikur Anbessa University Hospital, Ethiopia. Ethiop Med J 2010;48:11-21.

17. Abutaleb Arwa A, ALHadi Nusaybah F, Sadun Nouf S, Aldawsari Nouf M, Albalawi Ghadah A, Alnofaily Haider A, et al. Clinical epidemiology of neonatal sepsis among neonates admitted to King Khalid University Hospital in Riyadh. ECronicon Paediatrics 2018:48-57.

18. Jabiri A, Wella HL, Semiona A, Saria A, Protas J. Prevalence and factors associated with neonatal sepsis among neonates in Temeke and Mwananyamala Hospitals in Dar es Salaam, Tanzania. Tanzania J Health Res 2016;18(4).

19. Samaga MP. Prevalence of neonatal septicaemia in a tertiary care hospital in Mandya, Karnataka, India. Int J Res Med Sci 2016;4:2812-6.

20. West BA, Tabansi PN. Prevalence of neonatal septicaemia in the University of Port Harcourt Teaching Hospital, Nigeria. Niger J Paed 2014;41:32-7.

21. Leal YA, JoséÁlvarez-Nemegyei J, Velázquez JR, RosadoQuiab U, Diego-Rodríguez N, Paz-Baeza E, et al. Risk factors and prognosis for neonatal sepsis in southeastern Mexico. BMC Pregnancy Cildbirth 2012;12:48.

22. Shobowale EO, Solarin AU, Elikwu CJ, Onyedibe KI, Akinola IJ, Faniran AA. Neonatal sepsis in a Nigerian private tertiary hospital: bacterial isolates, risk factors, and antibiotic susceptibility patterns. Ann Afr Med 2017;16:52-8.

23. Leal YA, JoséÁlvarez-Nemegyei J, Velázquez JR, RosadoQuiab U, Diego-Rodríguez N, Paz-Baeza E, et al. Risk factors and prognosis for neonatal sepsis in southeastern Mexico. BMC Pregnancy Cildbirth 2012;12:48.

24. Woldu MA, Guta MB, Lenjisa JL, Tegegne GT, Dinsa H. Assessment of the incidence of neonatal sepsis, its risk factors, antimicrobials use and clinical outcomes in Bishoftu General 
Hospital, Neonatal Intensive Care Unit, Debrezeit-Ethiopia. Int J Contemp Pediatr 2014;1:135-41.

25. Mugalu J, Nakakeeto MK, Kiguli S, Kaddu-Mulindwa. DH. Aetiology, risk factors and immediate outcome of bacteriologically confirmed neonatal septicaemia in Mulago hospital, Uganda. Afr Health Sci 2015;6:120-6.

26. Siakwa M, Kpikpitse D, Mupepi S, Semuatu M.. Neonatal sepsis in rural Ghana: a case control study of risk factors in a birth cohort. Int J Res Med Health Sci. 2014;4:72-83.

27. Tewabe T, Mohammed S, Tilahun Y, Melaku B, Fenta M, Dagnaw T, et al. Clinical outcome and risk factors of neonatal sepsis among neonates in Felege Hiwot referral Hospital, Bahir Dar, Amhara Regional State, North West Ethiopia 2016: a retrospective chart review. BMC Res Notes 2017;10:265 